\title{
Symptomatic internal carotid artery dissection and kinking in a patient with fibromuscular dysplasia
}

\author{
Dissecção e acotovelamento sintomáticos da artéria carótida interna em paciente com \\ displasia ibromuscular
}

Victor Bilman¹ (D), Luca Apruzzi ${ }^{1}$ Domenico Baccellieri', Francesca Sanvito', Luca Bertoglio ${ }^{1}$, Roberto Chiesa ${ }^{1}$

\begin{abstract}
Isolated dissection of the internal carotid artery (ICA) is rare in young patients and is a cause for strong suspicion of fibromuscular dysplasia (FMD), especially when associated with artery elongation and tortuosity. The natural history of cerebrovascular FMD is unknown and management of symptomatic patients can be challenging. We report the case of a 44-year-old female patient with a history of transient ischemic attack in the absence of cardiovascular risk factors, associated with an isolated left ICA dissection and kinking. Carotid duplex ultrasound confirmed the diagnosis of dissection and demonstrated severe stenosis of the left ICA. The patient underwent surgical repair and histopathological evaluation confirmed the diagnosis of FMD with dissection. An autogenous great saphenous vein bypass was performed and the patient had an uneventful recovery. Cervical carotid artery dissection can be related to underlying arterial pathologies such as FMD, and the presence of ICA tortuosity highlights certain peculiarities for optimal management, which might be surgical.
\end{abstract}

Keywords: carotid artery; kinking; coiling; arterial dissection; fibromuscular dysplasia.

\begin{abstract}
Resumo
A dissecção isolada da artéria carótida interna em pacientes jovens é rara, e a displasia fibromuscular deve ser altamente suspeitada principalmente quando estiver associada a alongamento e tortuosidade da artéria. A história natural da displasia fibromuscular cerebrovascular é desconhecida, e o manejo de pacientes sintomáticos pode ser desafiador. Apresentamos o caso de uma paciente de 44 anos com histórico de ataque isquêmico transitório sem fatores de risco cardiovasculares, associado a dissecção e acotovelamento isolados da artéria carótida interna esquerda. O ultrassom duplo das carótidas confirmou o diagnóstico de dissecção e demonstrou estenose grave na artéria carótida interna esquerda. A paciente foi submetida a reparo cirúrgico, e a avaliação histopatológica confirmou o diagnóstico de displasia fibromuscular com dissecção. Foi realizada cirurgia de ressecção do segmento e reconstrução com veia safena magna autógena, e a paciente se recuperou sem complicações. A dissecção da artéria carótida cervical pode estar relacionada a doenças arteriais subjacentes, como a displasia fibromuscular, e a presença da tortuosidade da artéria carótida interna destaca algumas particularidades no manejo ideal, o qual pode ser cirúrgico.
\end{abstract}

Palavras-chave: artéria carótida; acotovelamento; enrolamento; dissecção arterial; displasia fibromuscular.

How to cite: Bilman V, Apruzzi L, Baccellieri D, Sanvito F, Bertoglio L, Chiesa R. Symptomatic internal carotid artery dissection and kinking in a patient with fibromuscular dysplasia. J Vasc Bras. 2021;20:e20200243. https://doi. org/10.1590/1677-5449.200243

1 "Vita - Salute" University, Scientific Institute H. San Raffaele, Milan, Italy.

Financial support: None.

Conflicts of interest: No conflicts of interest declared concerning the publication of this article.

Submitted: December 22, 2020. Accepted: February 25, 2021.

The study was carried out at San Raffaele Hospital, Milan, Italy.

Copyright $(2021$ The authors. This is an Open Access article distributed under the terms of the Creative Commons Attribution License, which permits unrestricted use, distribution, and reproduction in any medium, provided the original work is properly cited. 


\section{INTRODUCTION}

Isolated carotid artery elongation with coiling or kinking in the absence of atherosclerotic lesions is a rare condition and the correlation between carotid tortuosity and symptomatic cerebrovascular disease is still questionable. ${ }^{1,2}$ Fibromuscular dysplasia (FMD) might predispose to internal carotid artery tortuosity and, especially in case of extracranial carotid dissection, can be associated with cerebrovascular symptoms including headache, pulsatile tinnitus, transient ischemic attack (TIA), or stroke. ${ }^{3-6}$ According to the United States (US) FMD registry, $18.3 \%$ of strokes in young patients with FMD were related to arterial dissection, with carotid arteries involved in $13 \%$ of cases. $^{3}$

The best treatment of symptomatic patients with FMD and carotid tortuosity remains controversial and there are no randomized controlled trials comparing surgery vs. angioplasty in these conditions. ${ }^{2,4}$ Herein is reported the case of a young female patient, symptomatic for a TIA secondary to carotid artery dissection associated with kinking and FMD, who was successfully managed surgically by autogenous saphenous vein grafting.

\section{CASE REPORT}

A 44-year-old female, with no past medical history, was referred to our institution two weeks after a history of aphasia, a motor deficit of the right upper limb, and left non-pulsatile headache with complete resolution after 2 hours of duration. For these symptoms, she was admitted to another center, where a cerebral magnetic resonance angiography (MRA) showed recent areas of infarction in the territory of the left cerebral parietal lobe. Moreover, the MRA was negative for carotid and vertebral artery stenosis or dissection and positive for left internal carotid artery (ICA) kinking and concomitant right ICA coiling. She was kept in neurological intensive care for three days and discharged with dual antiplatelet therapy (Aspirin $100 \mathrm{mg}$ and Clopidogrel $75 \mathrm{mg}$ per day).

On presentation to our vascular surgery outpatient clinic, the patient was neurologically asymptomatic with normal blood pressure control and no history of other neurological events after discharge. A duplex ultrasound (DUS) of cervical arteries was performed and revealed severe kinking of the left internal carotid artery, according to the Metz classification, ${ }^{7}$ with an important decrease in the artery diameter $(>70 \%$ of stenosis) and a probable image of ICA dissection with thrombosis of the false lumen (Figure 1). The patient was promptly admitted for recovery, scheduled for surgery, and a new brain magnetic resonance imaging
(MRI) control was performed, showing no changes to the recent areas of infarct in the left parietal territory.

Under general anesthesia, with nasotracheal intubation, electroencephalogram (EEG), and near-infrared spectroscopy (NIRS) for continuous non-invasive neurological monitoring, the patient underwent left pre-sternocleidomastoid cervicotomy incision to expose the extracranial carotid artery. After obtaining proximal and distal artery control, under systemic heparinization, the left common carotid artery (CCA) and distal ICA were temporarily clamped. After performing a short arteriotomy, a 9Fr Pruitt-Inahara Carotid Shunt (LeMaitre Vascular, Inc. Burlington, Mass) was inserted and no significant neurological changes were observed on NIRS or EEG monitoring. The arterial wall in the dissected and kinked segments appeared very thin, and resection of that area was performed. Reconstruction of the ICA was performed with a bypass using the autogenous reversed great saphenous vein (Figure 2). There were no perioperative complications, and the patient had an uneventful recovery. The patient was discharged home on the fourth postoperative day on dual antiplatelet therapy.

At the 6-month follow-up control, the patient had no history of new neurologic events and DUS demonstrated a patent vein graft. (Figure 3) The resected segment of the ICA was sent to the Pathology Unit for histopathological evaluation, which reported ICA dissection, with focal loss of intima and media layers consistent with fibromuscular dysplasia (Figure 4). The patient consented to publication of this report.

\section{DISCUSSION}

Carotid artery dissection is a well-known cause of ischemic stroke among young and middle-aged individuals. ${ }^{8}$ Although the pathogenesis of carotid dissections remains unknown, numerous risk factors have been postulated such as connective tissue disorders, infection, neck trauma, common neck movements, and atherosclerosis. ${ }^{8}$ According to many authors, FMD predisposes to ICA dissection, which may be the first clinical presentation. ${ }^{3,4,6,9}$ Even though the most common clinical manifestations of cerebrovascular FMD are headaches, pulsatile tinnitus, and dizziness, according to a US FMD registry, 1 in 5 patients experience a dissection and cerebrovascular events including transient ischemic attack, stroke, and/or amaurosis fugax occur in 1 of every 4 patients with FMD. ${ }^{3}$

Generally, the natural course of cerebrovascular FMD is benign and it is mostly found incidentally. ${ }^{4}$ Several imaging methods are useful for detecting irregular patterns of stenosis and aneurysms in cerebrovascular FMD. As FMD mostly affects the middle and distal 


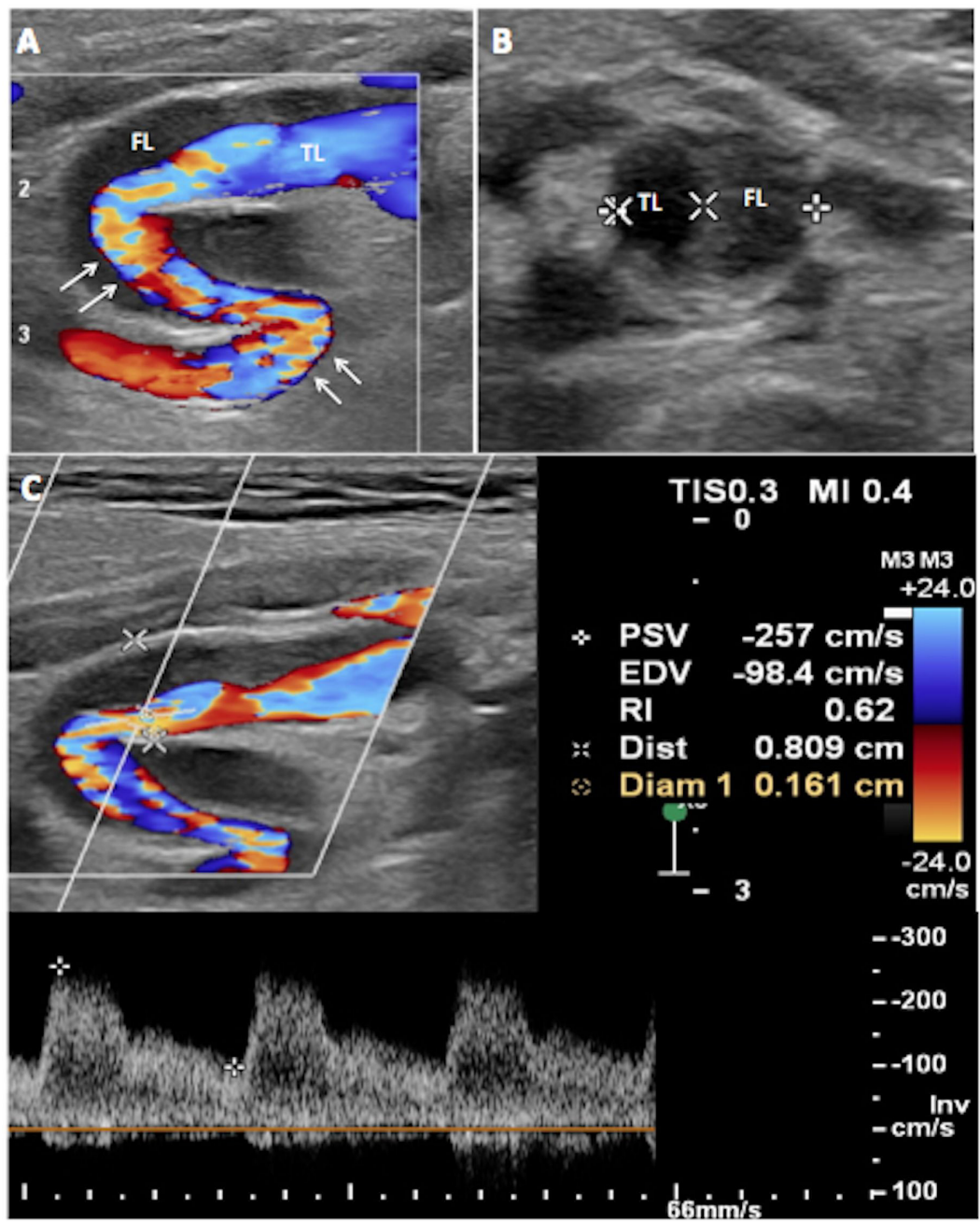

Figure 1. Preoperative Carotid Duplex Ultrasound. (A) There is turbulence (white arrows) in the left internal carotid artery (ICA) and tortuosity (S-curve morphology). The reduced arterial lumen caused by an arterial dissection is demonstrated, with false lumen (FL) and true lumen (TL); (B) Transverse view of the left ICA showing false lumen (FL) and true lumen (TL); (C) The spectral waveform shows markedly increased velocity of blood flow (PSV, peak systolic velocity $257 \mathrm{~cm} / \mathrm{s}$ ) and presence of spectral bruit, indicating high-grade arterial stenosis.
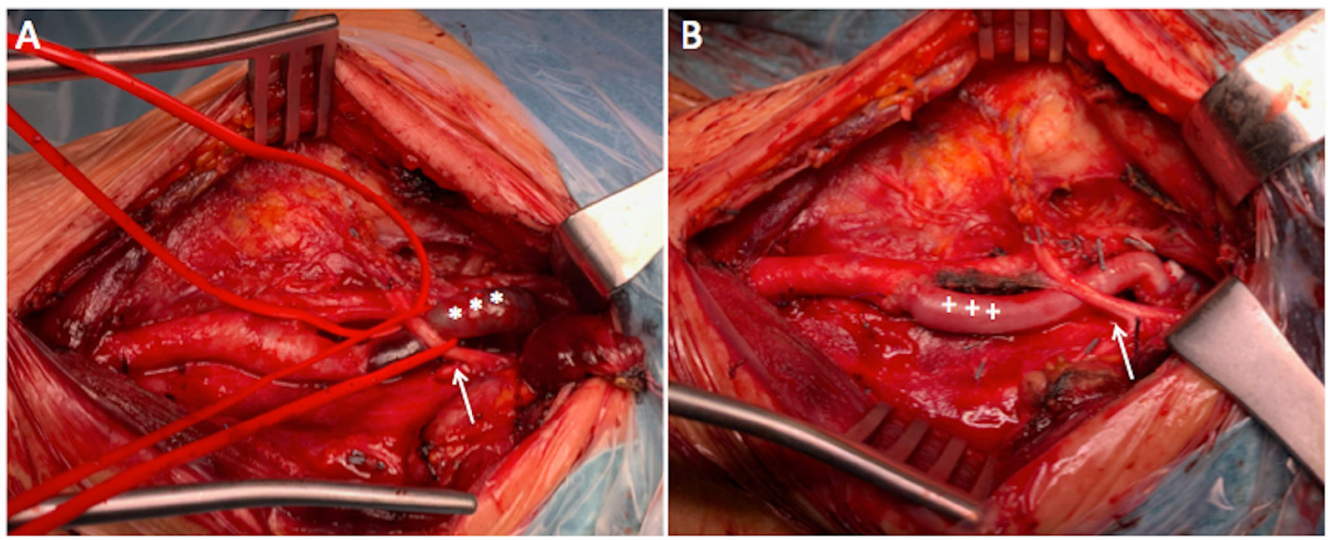

Figure 2. Intraoperative images. (A) Left carotid artery bifurcation showing dissection of the internal carotid artery with thrombosis of the false lumen (white asterisks); (B) Saphenous vein graft (white crosses) bypass from the carotid bifurcation to normal internal carotid artery. Hypoglossal nerve (white arrow). 

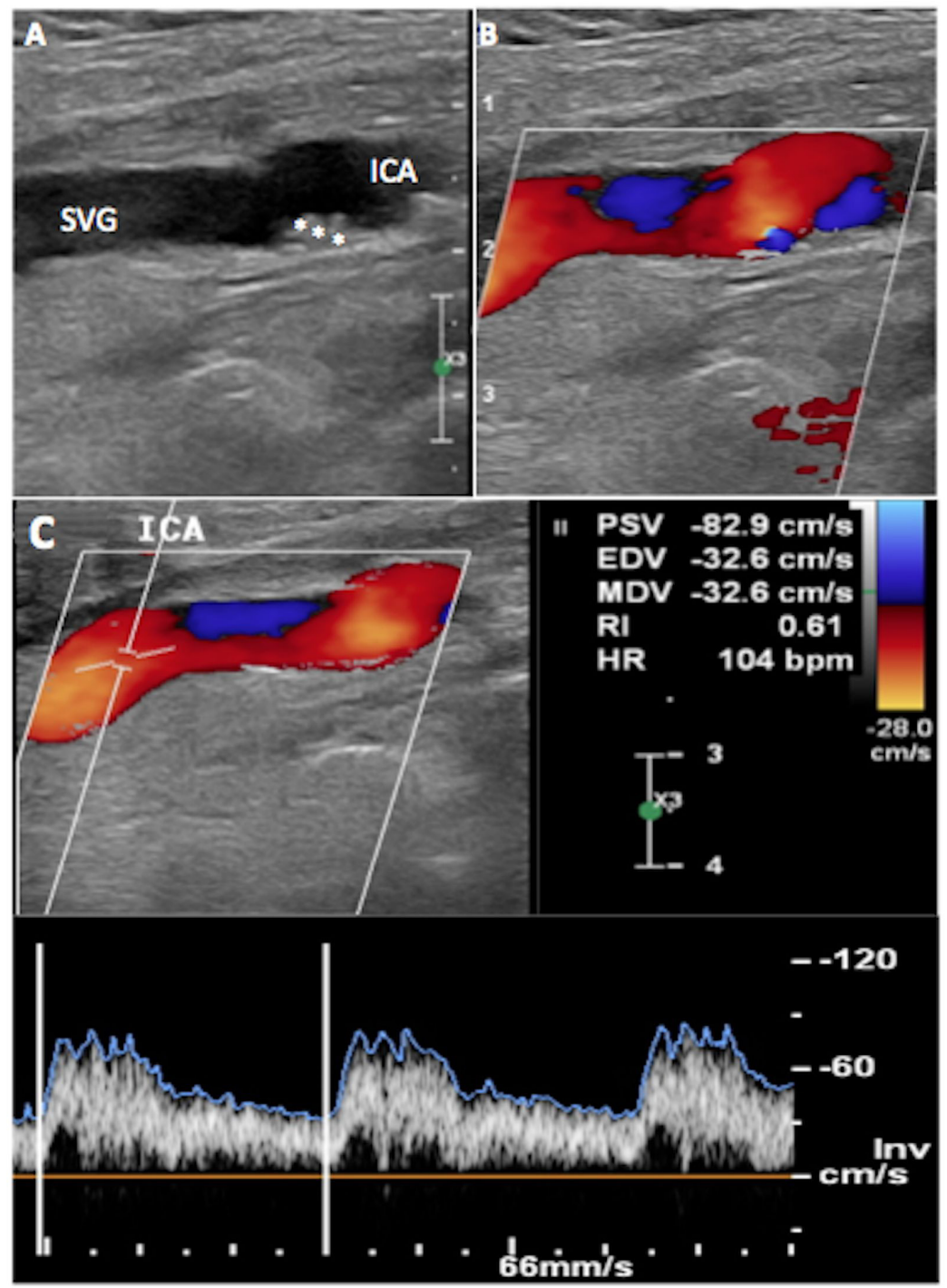

Figure 3.6-month post-operative carotid duplex ultrasound. (A) Saphenous vein graft (SVG) bypass to internal carotid artery (ICA). Anastomosis (white asterisks); (B) Patency of the SVG; (C) Spectral waveform showing normal blood flow velocity (PSV, peak systolic velocity $82.9 \mathrm{~cm} / \mathrm{s}$ ).

portions of the ICA, cervical DUS has low sensitivity for detecting its typical patterns, such as turbulence and tortuosity. Nevertheless, DUS offers an accurate noninvasive method for detecting associated carotid artery lesions, such as dissection, significant stenosis, and presence of atherosclerotic lesions. According to Sethi et al., 5 a distinct morphological appearance of the mid to distal ICA visualized on carotid DUS, forming the shape of an 'S' (S-shaped curve), has a significantly higher prevalence in FMD patients as compared to control groups. Although not specific, the presence of this S-curve morphology should be interpreted as an alert to a possible diagnosis of FMD. ${ }^{5}$ Additionally, MRA should be performed to rule out the presence of intracranial aneurysms in patients with FMD, despite being an inaccurate method for detecting cervical artery injuries. In this case, the two methods were complementary and it could therefore be advisable to use more than one imaging method for correct diagnosis and management.

According to some authors, FMD might genetically predispose patients to dolichoarteriopathies of the internal carotid artery (DICAs), a group of anomalies that can be divided into tortuosity, coiling, and kinking of the ICA. ${ }^{2,10}$ Ballotta et al. ${ }^{1}$ histologically evaluated surgically treated carotid elongations and found that $56 \%$ of patients in their cohort had an FMD pattern. Paltseva et al. ${ }^{11}$ demonstrated that FMD patients present with impaired vascular elasticity properties due to destruction of elastic fibers and a decreased 

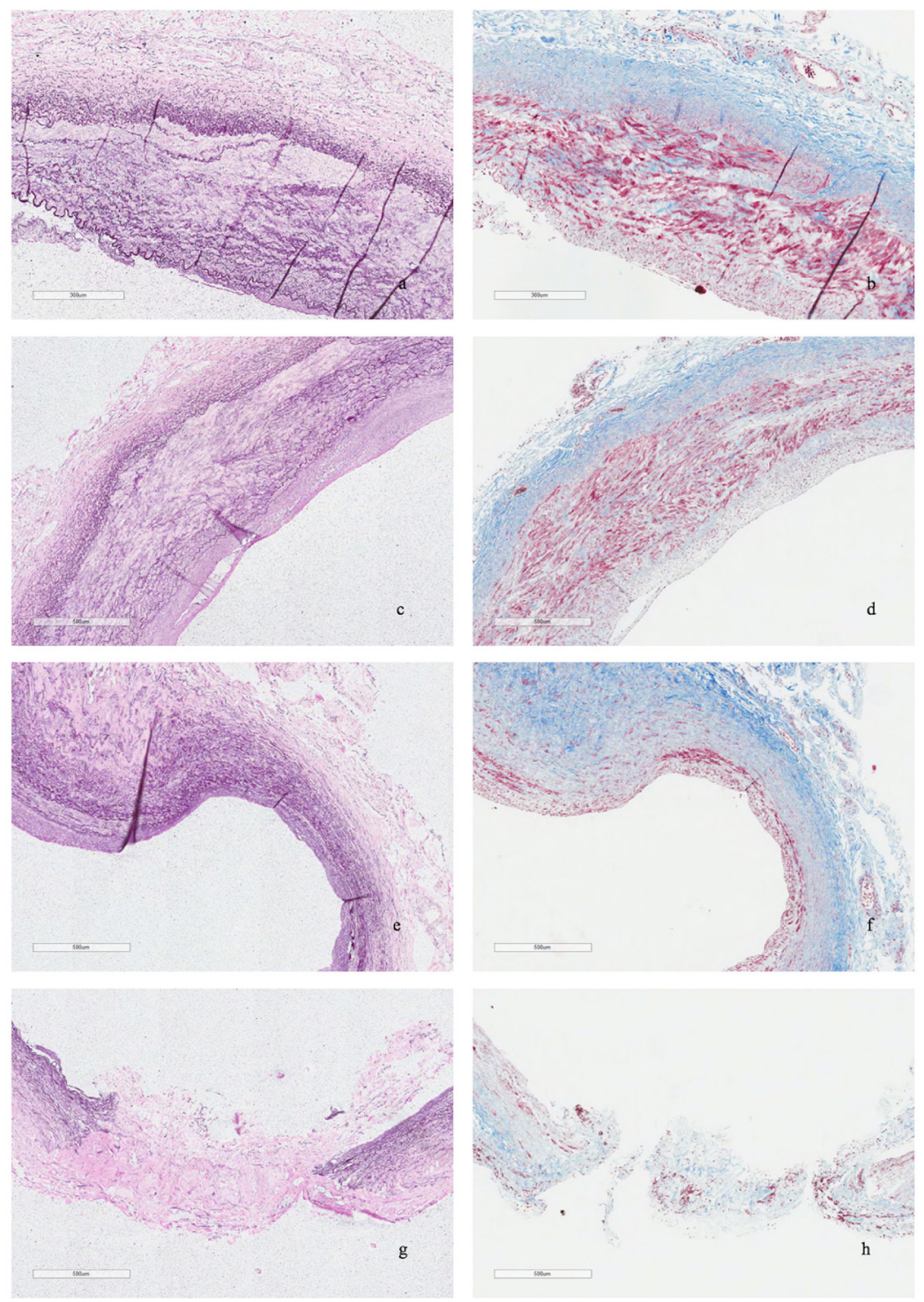

Figure 4. Histopathological evaluation. Elastic Van Gieson staining (a, c, e, g) and Masson trichrome staining (b, d, f, h) of carotid artery wall. Multifocal loss and fragmentation of elastic lamellae, severe disarray and loss of smooth muscle cells, leading to dilation and focal discontinuity of the media layer were observed. Minimal thickening and foamy macrophages were present in the intima layer. In a, b, c, d, $\mathbf{g}$, and $\mathbf{h}$ : bar= 500 micron; in $\mathbf{e}$ and $\mathbf{f}$ : bar=600 micron.

abundance of smooth muscle cells, which result in induction of tissue matrix degradation and could result in DICAs. ${ }^{2}$ The same histological pattern was observed in this case (Figure 4). These findings highlight the importance of correct FMD diagnosis, since this pathology involves multiple organs with increased risks of complications and death. ${ }^{1,4,5}$

After a suspicion or a definitive diagnostic of FMD, aggressive treatment of modifiable cardiovascular risk factors, such as hypertension, diabetes mellitus, and hyperlipidemia is supported and, in case of ischemic strokes, antithrombotic medications, including either antiplatelet therapy or anticoagulants are often administered. ${ }^{6}$ Assessment of the entire aorta and its branches with computed tomography (CT) or MRI is recommended for all FMD patients with strict annual DUS imaging surveillance unless new symptoms arise. ${ }^{6}$ According to Harriott et al., ${ }^{6}$ patients with cervical artery dissection should avoid activities that increase the risk of sudden, rapid, or severe neck motion or that raise intrathoracic or abdominal pressure.

To date, there have been no randomized controlled trials demonstrating the best treatment for symptomatic patients with cerebrovascular FMD. ${ }^{4,6}$ According to some authors, symptomatic patients have a low rate of symptom recurrence or disease progression and, 
therefore, could be managed conservatively with stroke risk modification, antiplatelet agents, and surveillance imaging. ${ }^{6}$ On the other hand, presence of ICA dissection and kinking requires surgical or endovascular treatment. ${ }^{2,4,6} \mathrm{In}$ recent decades, intraluminal angioplasty alone has been reported as the preferred treatment for FMD patients. ${ }^{4}$ However, the role of carotid angioplasty and stenting (CAS) in the management of severe ICA elongation in association with dissection is unclear. Whereas the endovascular approach has been described in a small cohort of patients with ICA dissection and tonsillar loop anatomy, it has not been reported in FMD patients. ${ }^{12}$ Moreover, the possibility of stent kinking due to the low radial force and vessel tortuosity could hinder catheter-guided procedures.

In this context, open surgery should be considered to treat the dissection and correct the ICA kinking or associated tortuosity. Surgical techniques include endto-end anastomosis, end-to-side ICA reimplantation, eversion or patch carotid endarterectomy, and grafting of autogenous saphenous vein or patch grafting, with resection of the excess ICA. ${ }^{2,4}$ In addition, the longterm durability of ICA reconstruction after open repair is crucial, considering the young mean age of FMD patients. In the case reported herein, the fragility of the carotid artery wall due to the dissection made primary anastomosis unfeasible and, therefore, saphenous vein bypass grafting with artery shortening was chosen.

\section{CONCLUSION}

Carotid artery dissection can be related to underlying pathologies such as FMD. In addition, the presence of ICA kinking and an S-curve pattern should be taken as an alert to the possibility of an FMD diagnosis. Surgical repair must be considered in symptomatic patients and histopathological evaluation is highly recommended to confirm the correct diagnosis and enable the best postoperative management.

\section{REFERENCES}

1. Ballotta $E$, Thiene $G$, Baracchini C, et al. Surgical vs medical treatment for isolated internal carotid artery elongation with coiling or kinking in symptomatic patients: a prospective randomized clinical study. J Vasc Surg. 2005;42(5):838-46. http://dx.doi.org/10.1016/j. jvs.2005.07.034. PMid:16275432.

2. Yu J, Qu L, Xu B, et al. Current understanding of dolichoarteriopathies of the internal carotid artery: A review. Int J Med Sci. 2017;14(8):77284. http://dx.doi.org/10.7150/ijms.19229. PMid:28824313.

3. Olin JW, Froehlich J, Gu X, et al. The United States registry for fibromuscular dysplasia: Results in the first 447 patients. Circulation. 2012;125(25):3182-90. http://dx.doi.org/10.1161/ CIRCULATIONAHA.112.091223. PMid:22615343.

4. Slovut DP, Olin JW. Fibromuscular dysplasia. N Engl J Med. 2004;350(18):1862-71. http://dx.doi.org/10.1056/NEJMra032393. PMid:15115832.
5. Sethi SS, Lau JF, Godbold J, Gustavson S, Olin JW. The S curve: a novel morphological finding in the internal carotid artery in patients with fibromuscular dysplasia. Vasc Med. 2014;19(5):356-62. http://dx.doi.org/10.1177/1358863X14547122. PMid:25135311.

6. Harriott A, Zimmerman E, Singhal AB, Jaff MR, Lindsay ME, Rordorf GA. Cerebrovascular fibromuscular dysplasia: the $\mathrm{MGH}$ cohort and literature review. Neurol Clin Pract. 2017;7(3):225-36. http:// dx.doi.org/10.1212/CPJ.0000000000000339. PMid:28680766.

7. Metz H, Bannister RG, Murray-Leslie RM, et al. Kinking of the internal carotid artery. Lancet. 1961;1(7174):424-6. http://dx.doi. org/10.1016/S0140-6736(61)90004-6. PMid:13769898.

8. Rubinstein SM, Peerdeman SM, Van Tulder MW, Riphagen I, Haldeman S. A systematic review of the risk factors for cervical artery dissection. Stroke. 2005;36(7):1575-80. http://dx.doi. org/10.1161/01.STR.0000169919.73219.30. PMid:15933263.

9. Poppe AY, Minuk J, Glikstein R, Leventhal M. Fibromuscular dysplasia with carotid artery dissection presenting as an isolated hemianopsia. j stroke cerebrovasc dis. 2007;16(3):130-4. http://dx.doi. org/10.1016/j.jstrokecerebrovasdis.2006.12.002. PMid:17689408.

10. La Barbera G, La Marca G, Martino A, et al. Kinking, coiling, and tortuosity of extracranial internal carotid artery: Is it the effect of a metaplasia? Surg Radiol Anat. 2006;28(6):573-80. http://dx.doi. org/10.1007/s00276-006-0149-1. PMid:17119858.

11. Paltseva EM, Oskolkova SA, Polyakova VO, et al. The structure of the internal carotid artery wall in pathological tortuosity. Arkh Patol. 2015;77(5):3-8. http://dx.doi.org/10.17116/patol20157753-8. PMid:26978013.

12. Rahal JP, Gao B, Safain MG, Malek AM. Stent recanalization of carotid tonsillar loop dissection using the enterprise vascular reconstruction device. J Clin Neurosci. 2014;21(7):1141-7. http:// dx.doi.org/10.1016/j.jocn.2013.11.007. PMid:24642024.

$\begin{array}{r}\text { Correspondence } \\ \text { Victor Bilman }\end{array}$
Department of Vascular Surgery, IRCCS H. San Raffaele
Via Olgettina, 60
CEP: 20132 - Milan, Italy
Tel: +390226437381
E-mail: vbilman@gmail.com
Author information
VB - Fellow division of Vascular Surgery, “Vita - Salute” University,
Scientific Institute H. San Raffaele.
LA, DB and LB - Chair division of Vascular Surgery, “Vita - Salute”
University, Scientific Institute H. San Raffaele.
FS - Chair pathology Unit, Division of Experimental Oncology, IRCCS
San Raffaele Hospital.
RC - Professor Division of Vascular Surgery, “Vita - Salute” University,
Scientific Institute H. San Raffaele.

Author contributions Conception and design: VB, LA, LB, DB Analysis and interpretation: VB, LA, LB, FS Data collection: VB, LA, FS Writing the article: $V B, L A, L B, F S$ Critical revision of the article: $L A, L B, D B, R C$ Final approval of the article*: LB, RC, DB Statistical analysis: N/A. Overall responsibility: $\vee B, R C$

*All authors have read and approved of the final version of the article submitted to J Vasc Bras. 